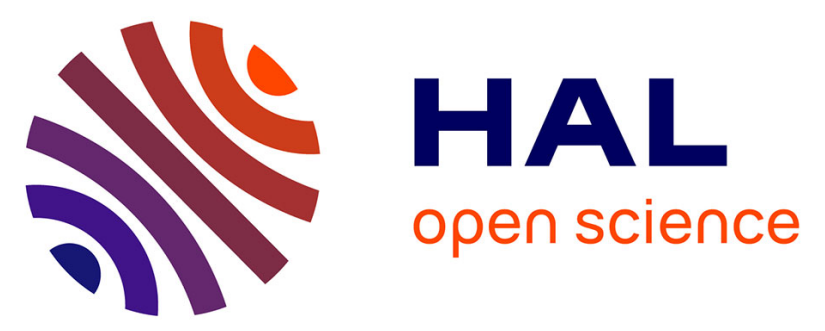

\title{
Liquid-Phase Synthesis, Sintering, and Transport Properties of Nanoparticle-Based Boron-Rich Composites
}

Guillaume Gouget, Damien Bregiroux, Rémi Grosjean, David Montero, Stefan Maier, Franck Gascoin, Clément Sanchez, David Portehault

\section{To cite this version:}

Guillaume Gouget, Damien Bregiroux, Rémi Grosjean, David Montero, Stefan Maier, et al.. LiquidPhase Synthesis, Sintering, and Transport Properties of Nanoparticle-Based Boron-Rich Composites. Chemistry of Materials, 2021, 33 (6), pp.2099-2109. 10.1021/acs.chemmater.0c04762 . hal-03214780

\section{HAL Id: hal-03214780 \\ https://hal.sorbonne-universite.fr/hal-03214780}

Submitted on 2 Sep 2021

HAL is a multi-disciplinary open access archive for the deposit and dissemination of scientific research documents, whether they are published or not. The documents may come from teaching and research institutions in France or abroad, or from public or private research centers.
L'archive ouverte pluridisciplinaire HAL, est destinée au dépôt et à la diffusion de documents scientifiques de niveau recherche, publiés ou non, émanant des établissements d'enseignement et de recherche français ou étrangers, des laboratoires publics ou privés. 


\title{
Liquid-Phase Synthesis, Sintering, and Transport Properties of Nanoparticle-Based Boron-Rich Composites
}

\author{
Guillaume Gouget, Damien Bregiroux, Rémi Grosjean, David Montero, Stefan Maier, Franck Gascoin, \\ Clément Sanchez, and David Portehault*
}

\begin{abstract}
Nanostructuring boron-rich materials should significantly impact their thermal and electrical transport properties. Nonetheless, nanostructured monoliths of such materials could not be achieved in the $10 \mathrm{~nm}$ range so far, because of the large temperatures required to synthesize and produce boron-rich compounds. Such a nanostructuration may have important consequences for achieving a trade-off between enhanced electrical and low thermal conductivity in boron-rich materials, which are among the few materials enabling thermoelectric power generation above $1000 \mathrm{~K}$ thanks to their thermal stability, high positive Seebeck coefficients, and low thermal conductivity. In this study, we use a one-pot synthesis in inorganic molten salts to yield a nanocomposite consisting of metallic $\mathrm{HfB}_{2}$ nanocrystals dispersed

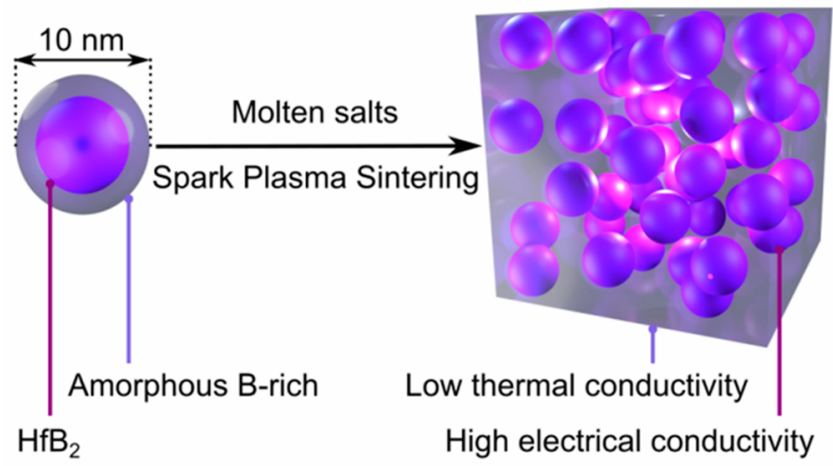
in an insulating amorphous boron-rich matrix with a controlled volume fraction of nanocrystals from 16 to 56 vol \%. We show that this controlled liquid-phase synthesis can be coupled to spark plasma sintering for densification preserving the nanostructure. The relationships between the reagent ratio in the liquid-phase synthesis, sintering conditions, and transport properties of the densified nanocomposites are then highlighted. We then design materials exhibiting metallic electrical conductivity related to the $\mathrm{HfB}_{2}$ nanocrystals, together with enhanced thermal dissipation attributed to the nanostructured amorphous boron matrix. Combined with the versatility offered by in-solution routes toward boride-based nanocomposites, this work opens a new avenue for tuning transport properties in boron-rich nanomaterials.
\end{abstract}

\section{INTRODUCTION}

Mastering simultaneously and independently thermal and electrical transport properties of materials is one central challenge underlying the design of thermoelectric materials. Overcoming this challenge is paramount in order to recover heat losses in transportation and industry ${ }^{1}$ and to complement energy conversion technologies such as photovoltaics. ${ }^{2}$ Nanostructuring thermoelectrics has enabled a significant increase in their performances, ${ }^{3}$ because it can minimize thermal conductivity without significantly impacting electrical conductivity, by lowering the contribution of phonons. ${ }^{4-8}$ This effect has been observed in many nanostructured materials targeting thermoelectric energy conversion at room temperature $(\mathrm{RT})^{9-11}$ and up to approximately $700 \mathrm{~K} .^{12-14}$ Much fewer studies address materials able to operate above $1000 \mathrm{~K}$, and they focus only on silicon nanostructured thermoelectrics. ${ }^{15}$ Combining materials with different properties at a length scale below $100 \mathrm{~nm}$ is one way to independently optimize thermal and electrical behaviors. ${ }^{11,16-18}$ Such nanocomposites were produced by using a conductive matrix embedding a variety of nanoparticles, like bismuth and antimony tellurides, ${ }^{11}$ tellurium, ${ }^{19}$ or polymers ${ }^{20}$ operating at temperatures well below $1000 \mathrm{~K}$. Very few nanocomposites able to operate above $1000 \mathrm{~K}$ have been reported so far. ${ }^{16}$ They are built from Si-based materials. ${ }^{16}$ Their fabrication is challenging due to the high temperatures required for processing and because the number of thermoelectric materials which are stable at such high temperatures is very limited, encompassing $\mathrm{Si}_{1-x} \mathrm{Ge}_{x},{ }^{21,22} \mathrm{Yb}_{14} \mathrm{MnSb}_{11}{ }^{23} \mathrm{Yb}_{4-x} \mathrm{Sm}_{x} \mathrm{Sb}_{3}$, ${ }^{24,25}$ $\mathrm{La}_{3-x} \mathrm{Te}_{4},{ }^{26} \mathrm{~B}_{6.5} \mathrm{C},{ }^{27}$ and $\mathrm{Ca}_{0.5} \mathrm{Sr}_{0.5} \mathrm{~B}_{6}{ }^{28,29}$ Boron-rich materials are pertinent candidates for high-temperature thermoelectric energy conversion because of their refractory properties and their high Seebeck coefficients. ${ }^{30-35}$ High temperature gradients (approximately $2000 \mathrm{~K}$ for boron carbides, for instance) can be applied, and consequently high thermoelectric efficiencies can be obtained (e.g., $\eta=25 \%$ for boron carbides), ${ }^{36}$ despite modest figures of merit. Among boron- 
rich solids, boron carbides are p-type conductors and alkaline earth metal hexaborides are n-type ones, ${ }^{28,29}$ both addressing the need for $\mathrm{p}$ - and n-type materials in thermoelectric devices. Nonetheless, their transport properties, including the nature of charge carriers, can hardly be controlled. Hence, new boronbased materials should be investigated for their thermoelectric properties with controlled charge carrier type.

The electrical and thermal transport properties of boronbased microstructured composites have been scarcely assessed, ${ }^{37,38}$ and no study has been reported on the transport properties of nanostructured boron-rich materials and on their nanocomposites. This is due to two obstacles: the scarcity of synthesis strategies toward B-rich compositions at the nanoscale ${ }^{39-41}$ and the difficulty to process these materials. ${ }^{42}$

The obstacle of the synthesis of nanostructured boron-rich solids is addressable by liquid-phase synthesis. Indeed, the formation of metal borides in inorganic salt melts ${ }^{43}$ yields nanocrystals with controlled sizes generally below $20 \mathrm{~nm}$ and adjustable compositions with various metals and metal-toboron stoichiometries (Figure 1). ${ }^{40,43,44}$ This one-step syn-

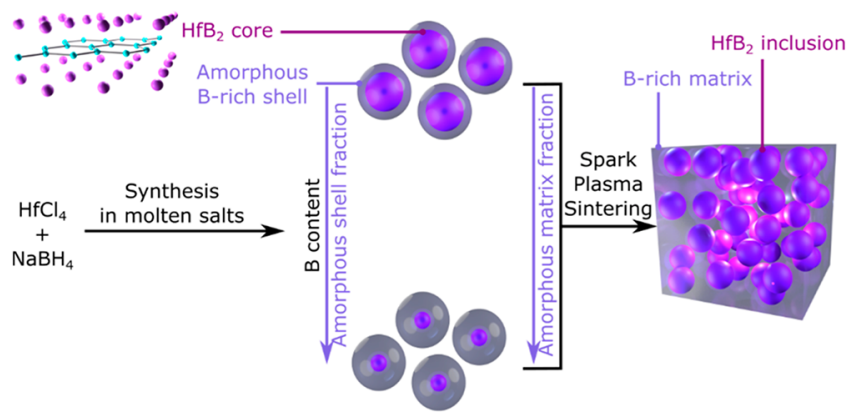

Figure 1. Scheme of the coupling process between synthesis of $\mathrm{HfB}_{2}$ nanocrystals in molten salts for the controlled composition of coreshell nanoparticles and spark plasma sintering for producing monoliths embedding conductive nanocrystals. In the $\mathrm{HfB}_{2}$ crystal structure, top left, $\mathrm{B}$ and $\mathrm{Hf}$ atoms are light blue and purple, respectively.

thesis systematically yields metal boride nanocrystals embedded in an amorphous boron-rich shell. This shell is prone to structural evolution when exposed to different atmospheres, temperatures, and pressures. ${ }^{45,46}$ Therefore, it should be possible to design innovative nanocomposites encompassing the metal boride nanocrystals and a surrounding matrix resulting from the initial shell.

The second obstacle relates to processing and is linked to the difficulty to sinter boron-rich compounds, which are refractory materials built on strong and directional covalent bonds. The high temperatures required for conventional sintering usually result in large grain sizes and loss of nanoscale features. $^{47}$ Spark plasma sintering (SPS) can overcome this limitation (Figure 1). It relies on pulsed current-based heating through the Joule effect in the sample and a graphite die. Because of the local heating, high heating rates are achieved and accompanied by efficient sintering at a lower temperature and shorter time compared to other hot-pressing techniques. These are key advantages to maintaining the nanostructure of materials. ${ }^{48-51}$ SPS can be adapted to the densification of ultrahard and refractory materials such as $\mathrm{ZrB}_{2}$ and $\mathrm{HfB}_{2}{ }^{37,52-54}$ Composites of yttrium borides doped with various p-block elements were also obtained by reactive SPS in previous works, where a chemical reaction occurred during sintering. ${ }^{47,55-57}$ Nonetheless, SPS has never been applied to target boron-rich composites nanostructured at the $10 \mathrm{~nm}$ length scale.

In the present work, we combine the synthesis in inorganic molten salts and spark plasma sintering to design nanocomposites (Figure 1) consisting of a dispersion of metallic $\mathrm{HfB}_{2}$ nanocrystals embedded in an insulating, amorphous boron-based matrix. The inclusion size and the volume fraction can be tuned, allowing a fine adjustment of the balance between the conductive and the insulating components. By enabling the decoupling between electrical and thermal transport, nanostructuration provides access to new multiphasic boron-rich materials with adjustable transport properties.

\section{RESULTS AND DISCUSSION}

\section{Controlling the Volume Fraction in $\mathrm{HfB}_{2}-$ Boron} Core-Shell Nanoparticles from Molten Salts. The synthesis of $\mathrm{HfB}_{2}$ core-shell nanoparticles in inorganic molten salts was adapted from previous studies. ${ }^{43}$ Briefly, various masses of $\mathrm{LiCl}, \mathrm{KCl}, \mathrm{HfCl}_{4}$, and $\mathrm{NaBH}_{4}$ anhydrous powders were ground and mixed together under an argon atmosphere (Table S1). The reaction mixtures were heated to $900{ }^{\circ} \mathrm{C}$ during $4 \mathrm{~h}$ and then cooled to room temperature (RT). The salts were dissolved in deionized water, and the resulting black powders were washed by successive steps of centrifugation and redispersion in deionized water. The samples were dried in a vacuum at $60{ }^{\circ} \mathrm{C}$. Before studying the effect of a change in the boron precursor proportion relative to hafnium, typical morphological and structural features of the products are described in Figure 2, starting with $2.00 \mathrm{mmol}$ of $\mathrm{HfCl}_{4}$ and $8.00 \mathrm{mmol}$ of $\mathrm{NaBH}_{4}$ (Hf:B molar ratio of 1:4). Transmission electron microscopy (TEM) data show that the powder encompasses polycrystalline aggregates (Figure $2 \mathrm{a}$ ) presenting a selected area electron diffraction (SAED) pattern, which can be fully indexed according to the $\mathrm{HfB}_{2}$ structure $(\mathrm{P} 6 / \mathrm{mmm})$. These aggregates are composed of spherical core-shell nanoparticles (Figure $2 \mathrm{~b}$ ). The core is made of an $\mathrm{HfB}_{2}$ single crystal, as confirmed by high-resolution TEM (Figure $2 \mathrm{c}$ ). The shell is amorphous and appears with a brighter contrast associated with a lower concentration of the heavy element hafnium compared to the core. The amorphous shell is continuous between two $\mathrm{HfB}_{2}$ nanocrystals, suggesting that the core-shell nanoparticles are irreversibly bound together. Energy-dispersive X-ray spectrometry (EDS) performed in a scanning electron microscope (SEM) indicates that hafnium, boron, and oxygen are the only elements detected, with an overall composition $\mathrm{Hf}_{0.2} \mathrm{~B}_{0.6} \mathrm{O}_{0.2}$ (Figure $\mathrm{S} 1$ ). Oxygen was reported to occur from the washing step with deionized water. ${ }^{43}$ No element from the inorganic solvent (neither chlorine nor any alkali element) is detected. The Hf:B molar ratio of 0.31 (3) from EDS is confirmed by the value of $0.36(2)$ obtained by ICP-OES. Both elemental analysis techniques confirm an excess of boron, in comparison to the nominal $\mathrm{HfB}_{2}$ stoichiometry. This boron excess (noted $\mathrm{B}_{\mathrm{am}}$ ) and the presence of oxygen account for the amorphous shell. ${ }^{43,58}$ The experimental ratio $O: B_{a m}$ is calculated from EDS data, after subtracting the $\mathrm{B}$ content involved in $\mathrm{HfB}_{2}$. The $\mathrm{O}: \mathrm{B}_{\mathrm{am}}$ ratio is $0.7(2)$, which is lower than the $\mathrm{O}: \mathrm{B}$ ratio of 1.5 in fully oxidized $\mathrm{B}_{2} \mathrm{O}_{3}$, indicating that boron is only partially oxidized in the shell. $43,45,46$

The initial Hf: $\mathrm{B}$ was varied from 1:3, i.e., 1.5 equiv of boron compared to the stoichiometry in $\mathrm{HfB}_{2}$, to $1: 12$, corresponding 


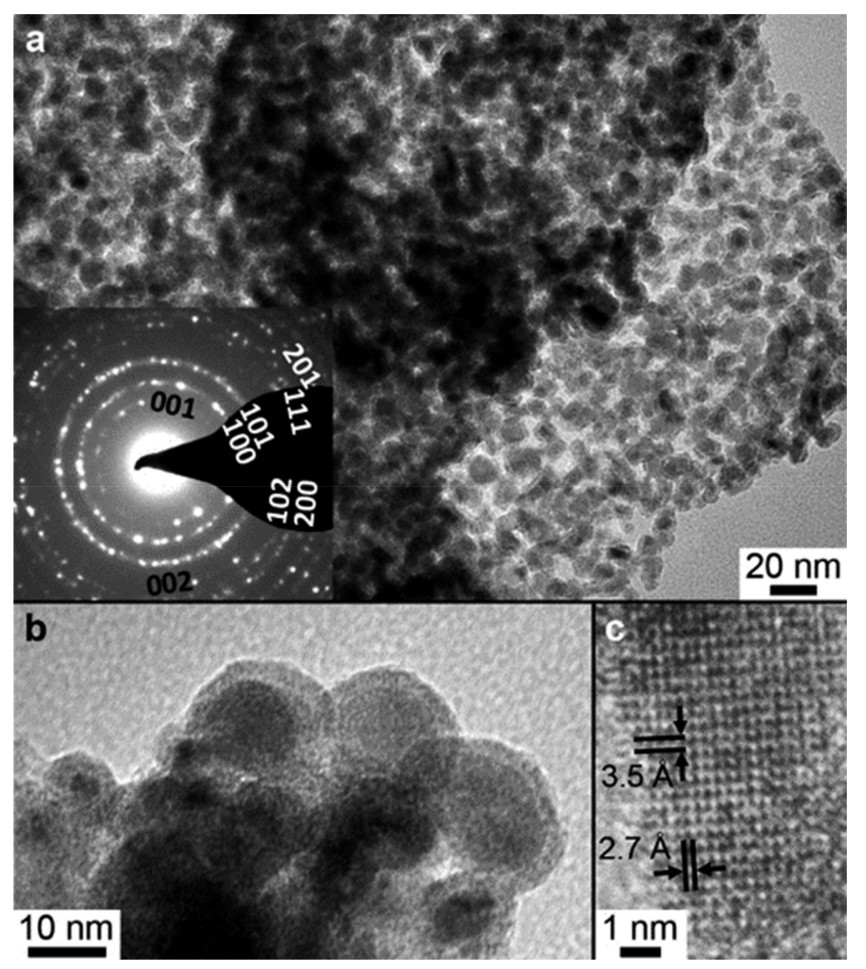

Figure 2. TEM micrographs of the $\mathrm{HfB}_{2}$-based nanocomposite obtained with an initial Hf:B molar ratio of 1:4. (a) Aggregate of nanoparticles and corresponding SAED (inset) pattern indexed according to the $\mathrm{HfB}_{2}$ structure. (b) Core-shell nanoparticles with the $\mathrm{HfB}_{2}$ core with higher contrast than the boron-rich shell. (c) HRTEM micrograph of a core with periodical ordering related to (001) and (100) (zone axis [010]) interreticular planes with 3.5 and $2.7 \AA$ spacings, respectively.

to 6 equiv. Hereafter, samples are named according to the initial Hf:B molar ratio. Powder XRD patterns (Figure 3) show that $\mathrm{HfB}_{2}$ is the only phase detected for samples $1: 4,1: 5,1: 6$, $1: 8$, and 1:12. For lower boron contents, a minor hafnium dioxide contamination is observed. Refined cell parameters of $\mathrm{HfB}_{2}$ are close to the reported values (Table S2) and do not depend significantly on the crystal size. The broadness of all $\mathrm{HfB}_{2}$ reflections increases with the initial boron concentration, which is associated with the decrease in the $\mathrm{HfB}_{2}$ apparent crystallite and particle size, as previously observed by TEM for $\mathrm{Hf}: \mathrm{B}$ ratios of $1: 4$ to $1: 12{ }^{40}$ The same trend is observed for $\mathrm{Hf}: \mathrm{B}$ ratios of $1: 3$ and $1: 3.5$ (Figure S2). Therefore, the $\mathrm{HfB}_{2}$ particle size can be tuned through the initial concentration of the boron precursor, borohydride. The average diameter of the core and the average thickness of the shell measured by TEM pictures (Figure S2) are plotted in Figure $4 \mathrm{a}$ as a function of the initial Hf:B molar ratio. For samples with a ratio between $1: 3$ and $1: 12$, the average core diameter is divided by about five from 13.0 to $2.3 \mathrm{~nm}$, whereas the shell thickness decreases only by approximately $30 \%$. As a result, the volume fraction of $\mathrm{HfB}_{2}$ (noted $\rho$ ) decreases (Figure $4 \mathrm{~b}$ ) with the $\mathrm{Hf}: \mathrm{B}=1: n$ ratio (increasing $n$ ), from $56 \%$ for sample $1: 3$ to $16 \%$ for $1: 12$. Hence, adjusting the boron precursor concentration enables tuning the volume fraction of metal boride in the amorphous partially oxidized boron matrix.

The two components of the nanocomposites formed by the synthesis in molten salts bear very different transport properties. Indeed, bulk $\mathrm{HfB}_{2}$ is a metallic conductor, ${ }^{52,59}$ while the shell consists of partially oxidized amorphous

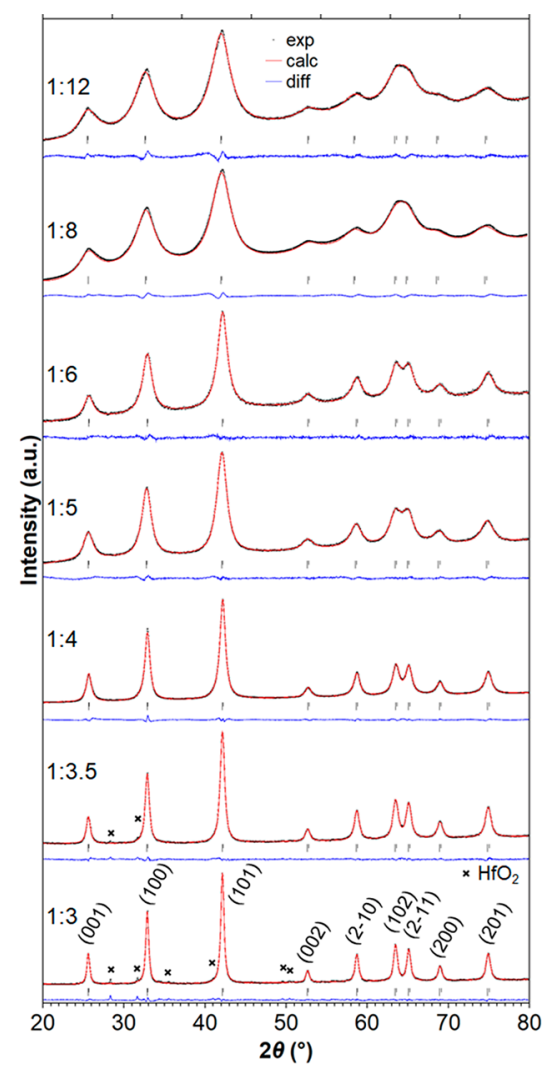

Figure 3. XRD patterns and Le Bail refinements of nanocrystalline $\mathrm{HfB}_{2}$ for various hafnium-to-boron molar ratios (Hf:B) of precursors initially introduced. Calculated reflections for $\mathrm{HfB}_{2}$ are indicated with vertical lines below diagrams.

boron. ${ }^{43,46}$ Related materials such as crystalline boron $(\beta$-B) and boron oxide glasses are electrical insulators with a low thermal conductivity, and $\beta$-B has a high Seebeck coefficient. $^{60,61}$ We took advantage of the control of the composition and nanostructure to study how the transport properties of these nanocomposites are affected by changes in $\mathrm{HfB}_{2}$ crystal size. Considering a monodisperse assembly of spheres, the theoretical three-dimensional percolation threshold corresponds to the volume fraction $\rho_{\text {thr. }}=34 \mathrm{vol} \%{ }^{62}$ Among the samples studied, the $\mathrm{HfB}_{2}$ volume fraction of $33 \mathrm{vol}$ $\%$ in sample 1:6 is the closest to $\rho_{t h r}$. Hence, we have focused our study on samples $1: 4$ and $1: 6$, corresponding to 41 and 33 vol $\%$ of conductive nanocrystals, i.e., well above and close to the percolation threshold, respectively. To achieve high densities while keeping the nanostructure of the composites unchanged, spark plasma sintering was favored over conventional hot-pressing for its ability to deliver homogeneous sintered monoliths that maintain the nanocrystalline particles within the nanocomposite. ${ }^{48-51}$

Densification by Spark Plasma Sintering. Sintering temperatures and pressures were screened in the $800-1800{ }^{\circ} \mathrm{C}$ and $100-130 \mathrm{MPa}$ ranges, respectively. The uniaxial pressure was applied at room temperature and maintained constant while the sample was heated to the target temperature under argon at $100{ }^{\circ} \mathrm{C} \cdot \mathrm{min}^{-1}$. The pressure was maintained for $1 \mathrm{~min}$ at the dwell temperature. The mechanical constraint was released at the end of the heat treatment, and the sample was then allowed to cool naturally to room temperature (RT). After a polishing step, cohesive pellets with different colors were recovered. Depending on the dwell temperature during 


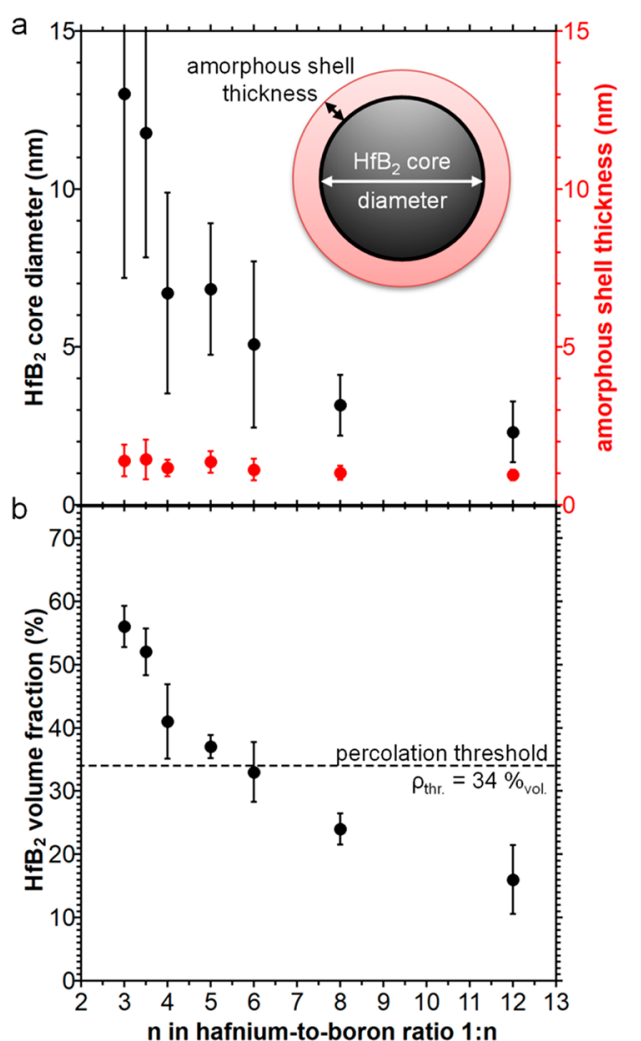

Figure 4. (a) Average core diameter and shell thickness of core-shell nanoparticles measured from TEM pictures including standard deviations. (b) Corresponding volume fraction $\rho$ of $\mathrm{HfB}_{2}$ cores in the nanocomposites as a function of the amount of boron precursor initially introduced. The theoretical percolation threshold (dashed line) represents the minimal volume fraction required for a monodisperse assembly of spheres to percolate within a threedimensional space.

SPS, they are matte black after a treatment at $800{ }^{\circ} \mathrm{C}$, brilliant black up to $1200{ }^{\circ} \mathrm{C}$, and metallic gray for $1350{ }^{\circ} \mathrm{C}$ and above (Figure S3). Figure 5 displays the XRD patterns of the initial

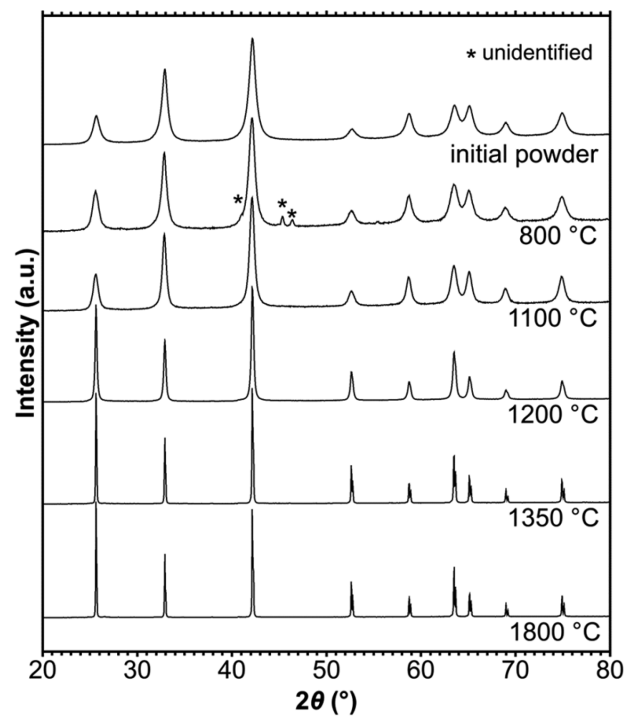

Figure 5. XRD patterns of the initial powder obtained with Hf:B = $1: 4$ and of pellets densified by SPS at various temperatures from 800 to $1800{ }^{\circ} \mathrm{C}$ under a uniaxial pressure of $100 \mathrm{MPa}$. powder 1:4 and of samples sintered at $100 \mathrm{MPa}$ and various temperatures. No reflection corresponding to crystalline boron could be detected. $\mathrm{HfB}_{2}$ remains the only crystalline phase after SPS, except after sintering at $800{ }^{\circ} \mathrm{C}$. This sample is contaminated with a minor unidentified phase, which is attributed to external contamination. With increasing sintering temperatures, XRD reflections sharpen due to crystal growth. The apparent crystallite size calculated using the Scherrer formula $^{63}$ shows a steep increase (Figure 6a) between 1200
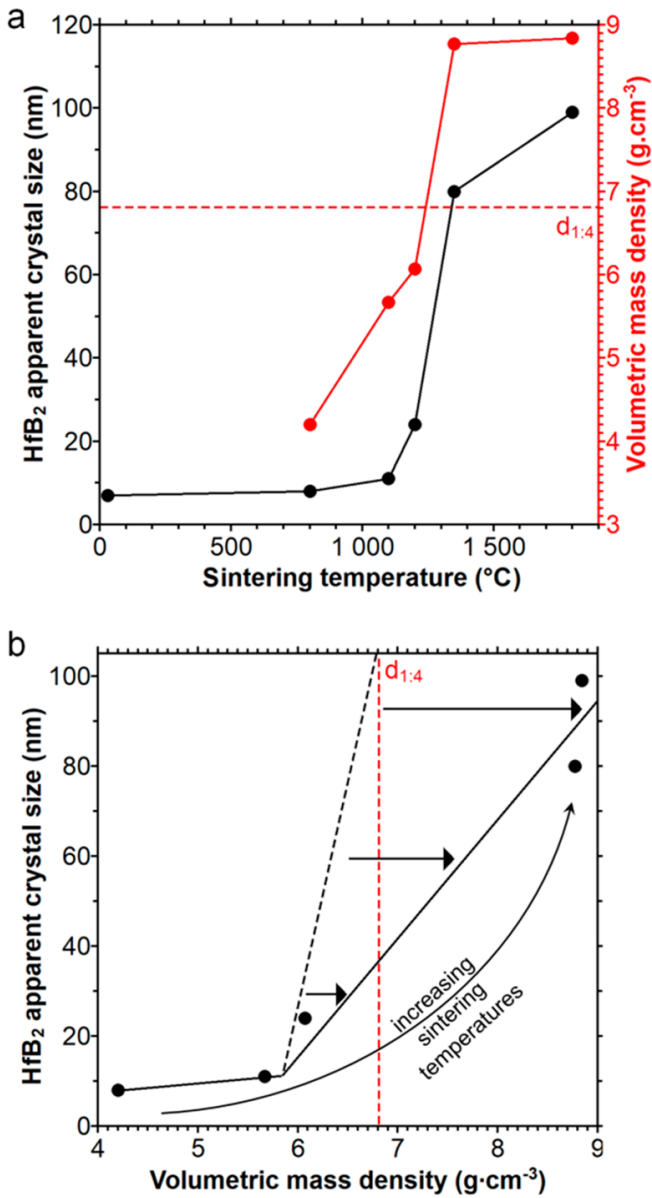

Figure 6. (a) $\mathrm{HfB}_{2}$ crystallite size and volumetric mass density of pellets obtained by SPS of powders with an initial Hf:B molar ratio $1: 4$ under a uniaxial pressure of $100 \mathrm{MPa}$ as a function of sintering temperature. (b) Crystal size as a function of pellet density. In the high density regime (high sintering temperature), values exceed the density of the initial powder $d_{1: 4}$ (red solid line), denoting a deviation (black arrows) from the expected sintering behavior (black dashed line). Experimental data points are connected by guide-to-the-eye lines.

and $1350{ }^{\circ} \mathrm{C}$ from 24 to $80 \mathrm{~nm}$. Above $1350{ }^{\circ} \mathrm{C}$, the Scherrer formula reaches its limits of applicability, which is associated with the instrumental broadening for crystal growth above the nanometer size range.

The volumetric mass density of the pellets resulting from SPS was measured by hydrostatic pycnometry (Figure 6a). The density increases linearly up to $1200{ }^{\circ} \mathrm{C}$ and then increases abruptly before reaching a plateau at approximately $9 \mathrm{~g} \cdot \mathrm{cm}^{-3}$. Between 1200 and $1350^{\circ} \mathrm{C}$, the highest increase rate in density is accompanied by the highest rate in crystal growth. The apparent crystal size plotted as a function of density (Figure 6b) shows two successive regimes: densification with limited 
crystal growth at low temperatures and densification accompanied by a stronger crystal growth at $1350{ }^{\circ} \mathrm{C}$ and above. The volumetric mass densities of pellets sintered at 1350 and $1800{ }^{\circ} \mathrm{C}$ (respectively 8.77 and $8.84 \mathrm{~g} \cdot \mathrm{cm}^{-3}$ ) are approximately $30 \%$ higher than the volumetric mass density of the initial powder $d_{1: 4}=6.81 \mathrm{~g} \cdot \mathrm{cm}^{-3}$, measured by helium pycnometry, which enables accessing open pores in the subnanometer range (kinetic diameter of $2.6 \AA) .{ }^{64}$ This high-temperature densification is unusual compared to a common behavior, indicated by a dotted black line, where the upper limit of the density of the pellet is expected to be the density of the powder measured by He pycnometry. ${ }^{65}$ This behavior is reflected in the withdrawal of the piston mold during SPS (Figure S3): two successive shrinkages occur around 800 and $1000{ }^{\circ} \mathrm{C}$ for pellets sintered at 1100 and 1200 ${ }^{\circ} \mathrm{C}$, which enable both densifying the material and keeping $\mathrm{HfB}_{2}$ nanocrystals with only slight crystal growth (Figure 6). An additional shrinkage is observed above $1300{ }^{\circ} \mathrm{C}$ for pellets sintered at 1350 and $1800{ }^{\circ} \mathrm{C}$ (Figure S3). This hightemperature densification was further examined by analyzing the nanostructure of the SPS pellets using scanning electron microscopy (SEM).

The pellets were investigated from their basal surface (Figure S4) after polishing. Near-spherical nanoparticles with a diameter around $10 \mathrm{~nm}$ as in the initial 1:4 powder (Figure 2, Figure $7 \mathrm{a}$ ) are maintained for the sample sintered at $1100{ }^{\circ} \mathrm{C}$,

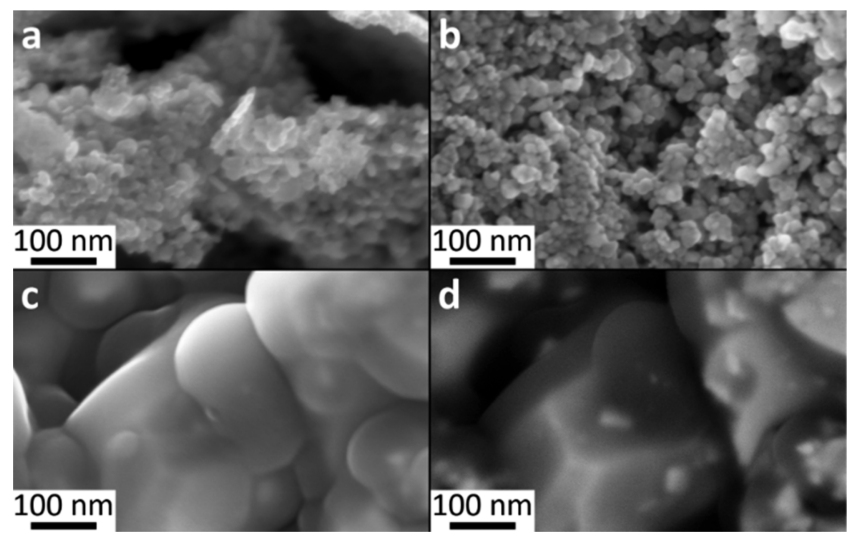

Figure 7. SEM-FEG micrographs of (a) the initial powder with the Hf:B molar ratio of 1:4, and the resulting pellets after SPS under 100 $\mathrm{MPa}$ at (b) $1100{ }^{\circ} \mathrm{C}$ and (c, d) $1800{ }^{\circ} \mathrm{C}$. The exact same region is analyzed in $(\mathrm{c})$ and $(\mathrm{d})$. The images are acquired in $(\mathrm{a}-\mathrm{c})$ secondary electron and (d) backscattered electron modes.

as observed in scratched out areas in Figure $7 \mathrm{~b}$. The pellet obtained at $1800{ }^{\circ} \mathrm{C}$ is composed of particles with sizes between $50 \mathrm{~nm}$ and $1 \mu \mathrm{m}$ (Figure 7c). Imaging in backscattered electron mode provides the chemical contrast between hafnium- and boron-rich regions, where dark contrast areas in Figure 7d (see also Figure S4c) are poor in hafnium and rich in light elements, assigned to boron, while bright particles are assigned to $\mathrm{HfB}_{2}$. Therefore, the nanostructure of the powder constituted of $10 \mathrm{~nm}$ core-shell nanoparticles is maintained at $1100{ }^{\circ} \mathrm{C}$ but turns into a dense mixture of $\mathrm{HfB}_{2}$ and boron-rich submicrometer particles after sintering at 1800 ${ }^{\circ} \mathrm{C}$ : elemental heterogeneity is observed at the submicrometer scale. Not only do $\mathrm{HfB}_{2}$ nanocrystals grow during SPS at 1800 ${ }^{\circ} \mathrm{C}$, but elemental segregation also occurs in the boron-rich amorphous matrix. Overall, a sintering temperature below
$1200{ }^{\circ} \mathrm{C}$ is necessary to prevent the sample from elemental segregation and to ensure a preserved nanostructure.

The high-temperature densification phenomenon observed above $1200{ }^{\circ} \mathrm{C}$ is accompanied by extensive crystal growth and a large increase of the pellet density above the He pycnometrymeasured density of the pristine powder. By considering that the composite is made of $\mathrm{HfB}_{2}\left(11.21 \mathrm{~g} \cdot \mathrm{cm}^{-3}\right)^{52}$ and boron $\left(2.37 \mathrm{~g} \cdot \mathrm{cm}^{-3}\right)^{31}$ with the overall Hf:B ratio measured by EDS, we evaluate the expected density $d_{\text {thr }}$ to $9.21 \mathrm{~g} \cdot \mathrm{cm}^{-3}$ (calculation detailed in the Experimental Section). After the high-temperature densification event (Figure 6b), the pellet densities are 8.75 and $8.84 \mathrm{~g} \cdot \mathrm{cm}^{-3}$ at 1350 and $1800{ }^{\circ} \mathrm{C}$, respectively. These values represent 95 and $96 \%$ of $d_{\mathrm{thr}}$, respectively. According to XRD, SEM, and density measurements, the high temperature pellets obtained above 1350 and $1800{ }^{\circ} \mathrm{C}$ are then consistent with $\mathrm{HfB}_{2}$ and amorphous boron submicrometer particles. The $\mathrm{HfB}_{2}$ phase is maintained at all temperatures, which is in agreement with its refractory properties. $^{53,54}$

The calculations presented above show that the density $d_{1: 4}$ of the pristine sample at room temperature is inconsistent with a sample made of $\mathrm{HfB}_{2}$ and reported amorphous boron. ${ }^{31,52}$ Because the $\mathrm{HfB}_{2}$ structure is verified by XRD, the observed deviation of the density versus the ideal case must relate to the amorphous shell. Taking into account the density of boron oxide or boric acid to correct for the oxidized fraction of boron in the shell cannot explain the surprisingly low density of the 1:4 powder. Hence, the $d_{1: 4}$ value can be explained either by closed pores that cannot be probed by helium pycnometry or by a local structure different than those tabulated for amorphous boron. The hypothesis of closed porosity can be discarded because such pores would be filled with salts from the synthesis or deionized water from the washing step, while none of these species could be detected in sufficient amounts to explain the density values (EDS does not show any salt and the oxygen content is not consistent with $30 \mathrm{wt} \%$ of water needed to reach such low density values). Therefore, we propose that the initial amorphous shell embedding the $\mathrm{HfB}_{2}$ nanoparticles in the pristine powder is constituted of a lowdensity form of partially oxidized elemental boron. Further efforts will be needed in the future to investigate the structural features of this elemental boron form. ${ }^{11} \mathrm{~B}$ NMR and XPS data suggest that oxidized boron species are already chemically similar to borates. ${ }^{43,46}$ Partial oxidation of the initial amorphous shell is supported by the observation that the low temperature sintering events at $800-900{ }^{\circ} \mathrm{C}$ are accompanied by the formation of a white deposit on the outer parts of the mold, typical of boron oxide, which is volatile in the conditions of SPS sintering. ${ }^{46,66,67}$ We hypothesize that oxidized boron species are eliminated during SPS, yielding a nanocomposite of $\mathrm{HfB}_{2}$ and elemental amorphous boron.

While the amorphous component is constituted of common elemental boron above $1350{ }^{\circ} \mathrm{C}$ and by a low density form in the initial powder, the nature of this amorphous component must be questioned for the low temperature pellets obtained at 800,1100 , and $1200{ }^{\circ} \mathrm{C}$. The high-temperature densification event is accompanied by elemental segregation leading to the loss of core-shell architecture, large $\mathrm{HfB}_{2}$ grain growth, and amorphous submicrometer boron particles. These abrupt changes suggest a correlation to structural transformations in the amorphous component and thus suggest that the samples sintered at lower temperature still encompass the low-density form detected in the powder at room temperature. This 
hypothesis is supported by the only slight particle growth occurring during sintering at these temperatures, which shows that no extensive restructuration has taken place. Likewise, these low-temperature pellets are cohesive, and the samples obtained at 1100 and $1200{ }^{\circ} \mathrm{C}$ exhibit bright faces and only a few pores according to SEM (Figure S4), showing efficient densification. Therefore, by taking into account the density of the initial powder $1: 4$, the 800,1100 , and $1200{ }^{\circ} \mathrm{C}$ pellets correspond to a densification of 62,83 and $89 \%$, respectively (Table 1).

Table 1. $\mathrm{HfB}_{2}$ Apparent Crystal Size and Density of Pellets Sintered from Two Boron-Rich Nanocomposites (Hf:B) under Various Sintering Pressures $(P)$ and Temperatures (T)

$\begin{array}{ccc}\begin{array}{c}\text { sample } \\ \text { Hf:B-T }\left({ }^{\circ} \mathrm{C}\right)-P \\ (\mathrm{MPa})\end{array} & \begin{array}{c}\mathrm{HfB}_{2} \text { size } \\ (\mathrm{nm})\end{array} & \begin{array}{c}\text { volumetric mass } \\ \text { density }\left(\mathrm{g} \cdot \mathrm{cm}^{-3}\right)\end{array} \\ 1: 4^{a} & 7 & 6.81 \\ 1: 6^{a} & 5 & 4.12 \\ 1: 4-800-100 & 8 & 4.20 \\ 1: 4-1100-100 & 11 & 5.67 \\ 1: 4-1100-130 & 18 & 6.02 \\ 1: 4-1200-100 & 24 & 6.07 \\ 1: 6-1200-100 & 9 & 4.27 \\ \text { Pristine powders. } & & \end{array}$

temperature in Figure 8. Corrections from porosity effects were applied following the Maxwell-Eucken equation (details can
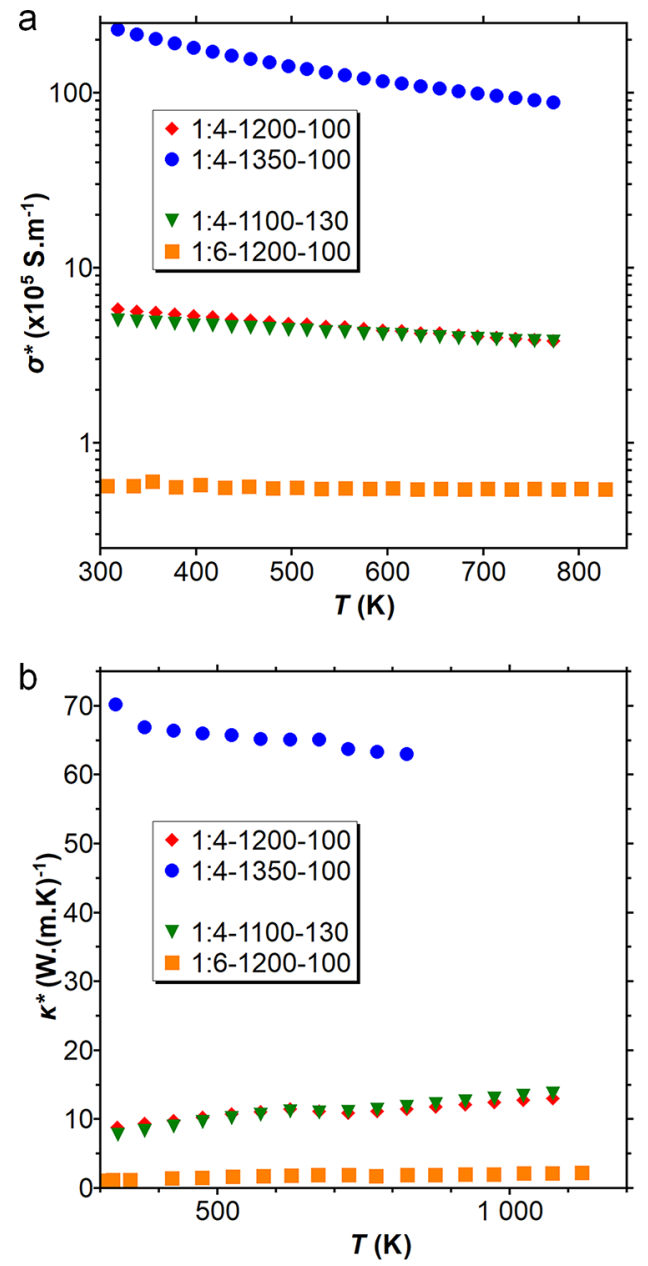

Figure 8. Thermal dependence of (a) electrical and (b) thermal conductivities in boron-rich dense nanocomposites (Hf:B- $T\left({ }^{\circ} \mathrm{C}\right)-\mathrm{P}$ $(\mathrm{MPa})$ ). The values are corrected from the contribution of pores by using the Maxwell-Eucken equation.

be found in the Experimental Section). Electrical and thermal conductivities vary by ca. 2 orders of magnitude, depending on the initial hafnium-to-boron ratio and sintering conditions. We focus first on samples with an Hf:B initial ratio of $1: 4$ at 100 $\mathrm{MPa}$. After sintering at $1350{ }^{\circ} \mathrm{C}$, both conductivity values $(9 \times$ $10^{6}<\sigma^{*}<2.3 \times 10^{7} \mathrm{~S} \cdot \mathrm{m}^{-1}$ and $\left.63<\kappa^{*}<70 \mathrm{~W} \cdot \mathrm{m}^{-1} \cdot \mathrm{K}^{-1}\right)$ and their thermal dependence between room temperature and 700 $\mathrm{K}$ are similar to those of bulk $\mathrm{HfB}_{2}\left(6.7 \times 10^{6}<\sigma^{*}<1.7 \times 10^{7}\right.$ $\mathrm{S} \cdot \mathrm{m}^{-1}$ and $\left.70<\kappa^{*}<100 \mathrm{~W} \cdot \mathrm{m}^{-1} \cdot \mathrm{K}^{-1}\right),{ }^{52,59}$ indicating a metallic behavior consistent with the large $\mathrm{HfB}_{2}$ grain growth described above. The metallic behavior is also observed after sintering at $1800{ }^{\circ} \mathrm{C}$ (Figure S6). Decreasing the sintering temperature down to $1200{ }^{\circ} \mathrm{C}$ leads to a decrease of both electrical and thermal conductivities by 1 order of magnitude. The thermal dependence of the thermal conductivity corrected from porosity $\left(\kappa^{*}\right)$ changes drastically and especially deviates from bulk $\mathrm{HfB}_{2}{ }^{59}$ The electrical conductivity corrected from porosity $\left(\sigma^{*}\right)$ is around $4 \times 10^{5} \mathrm{~S} \cdot \mathrm{m}^{-1}$ and still shows a metallic temperature dependence, suggesting that the decrease in conductivity with the decrease of the sintering temperature from 1350 to $1200{ }^{\circ} \mathrm{C}$ originates from fewer electronic 
percolation paths between $\mathrm{HfB}_{2}$ nanocrystals, in agreement with their smaller particle size. Decreasing the sintering temperature further from 1200 to $1100{ }^{\circ} \mathrm{C}$ leads to a decrease in electrical conductivity by 1 order of magnitude and no significant temperature dependence. This low electrical conductivity is in agreement with smaller $\mathrm{HfB}_{2}$ nanocrystals and inefficient percolation of conduction paths. Furthermore, an increase of the pressure from 100 to $130 \mathrm{MPa}$ enables recovering at low sintering temperature (1:4-1100-130) the transport properties of a higher temperature pellet at $100 \mathrm{MPa}$ (1:4-1200-100), in agreement with their similar nanostructures. Finally, increasing the boron content from 1:4 (1:41200-100) to $1: 6(1: 6-1200-100)$ leads to electrical and thermal conductivities decreased by 1 order of magnitude, in agreement with the higher volume fraction of the electrically and thermally insulating matrix. Overall high $\mathrm{HfB}_{2}$-related electrical conductivities in the $0.4 \times 10^{5}-4 \times 10^{5} \mathrm{~S} \cdot \mathrm{m}^{-1}$ range are maintained in the nanocomposites, accompanied by low thermal conductivities in the $1-10 \mathrm{~W} \cdot \mathrm{m}^{-1} \cdot \mathrm{K}^{-1}$ range. Thermal conductivity switches from a metallic behavior when the $\mathrm{HfB}_{2}$ size is on the submicrometer size range and amorphous boron is segregated, to a nonmetallic one when the nanocomposite is maintained for low sintering temperatures.

Seebeck coefficients $S$ measured as a function of temperature (Figure 9) are negative, indicating that electrons are the

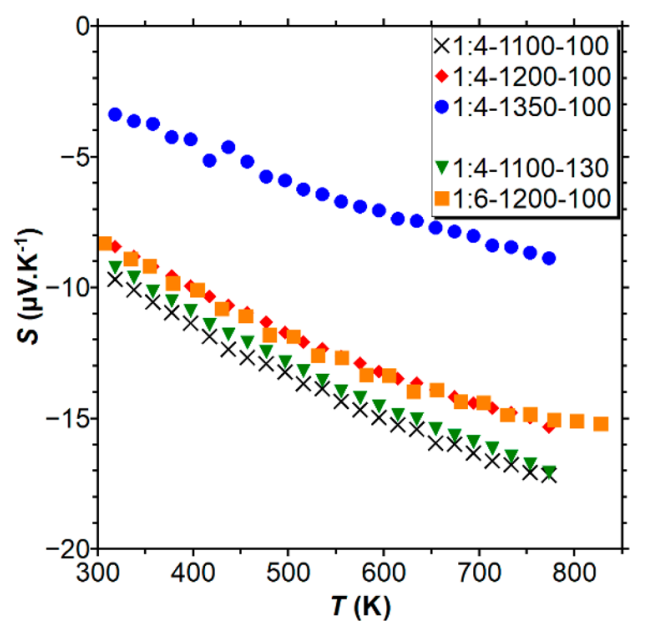

Figure 9. Thermal dependence of Seebeck coefficient in boron-rich dense nanocomposites (Hf:B-T $\left({ }^{\circ} \mathrm{C}\right)-P(\mathrm{MPa})$ ).

majority carrier type as expected from the metallic conductivity. Accordingly, sintering above $1350{ }^{\circ} \mathrm{C}$ yields $S$ values typical for metals. ${ }^{68,69}$ Absolute $S$ values at RT are approximately three times larger in samples sintered at 1200 ${ }^{\circ} \mathrm{C}$ and below. They also increase when lowering the temperature of sintering from 1200 to $1100{ }^{\circ} \mathrm{C}$, showing a larger contribution of the insulating matrix, as expected from the maintained nanostructure. As long as the nanostructure is kept in the composite, the Seebeck coefficient is independent of the sintering pressure and the Hf:B ratio. Low $S$ values result in low thermoelectric figures of merit $Z T$ of ca. 0.01 at $1000 \mathrm{~K}$ calculated by extrapolating $\sigma$ and $S$ dependences with the temperature. These modest values are not surprising given that $\mathrm{HfB}_{2}$ systematically rules over the electrical behavior, even for a relatively high content of amorphous boron matrix. The samples all exhibit pronounced metallic behavior evidenced by electrical conductivity and Seebeck coefficient measurements.
On the contrary, the thermal conduction behavior in nanocomposites is changed compared to the bulk sample, suggesting that it is impacted by the amorphous matrix.

Although the Seebeck coefficient is low, it is informative to highlight the ability to decouple the electrical $\sigma$ and thermal $\kappa$ conductivities by calculating the $\sigma / \kappa$ ratio (Table 2 ). Bulk

Table 2. Transport Properties at $1000 \mathrm{~K}^{a}$ of Boron-Rich Dense Nanocomposites and Some Other Boron-Based Materials from Literature

$\begin{array}{cccll}\begin{array}{c}\text { sample Hf:B-T }\left({ }^{\circ} \mathrm{C}\right)-P \\ (\mathrm{MPa})\end{array} & \text { type } & \kappa\left(\mathrm{W} \cdot \mathrm{m}^{-1} \cdot \mathrm{K}^{-1}\right) & \sigma\left(\mathrm{S} \cdot \mathrm{m}^{-1}\right) & \begin{array}{c}\sigma / \kappa \\ \left(\mathrm{S} \cdot \mathrm{K} \cdot \mathrm{W}^{-1}\right)\end{array} \\ 1: 4-1200-100 & \mathrm{n} & 12.8 & 2.8 \times 10^{5} & 3.3 \times 10^{4} \\ 1: 4-1100-130 & \mathrm{n} & 13.4 & 2.7 \times 10^{5} & 3.7 \times 10^{4} \\ 1: 6-1200-100 & \mathrm{n} & 2.1 & 5.5 \times 10^{4} & 2.8 \times 10^{4} \\ \beta-\mathrm{B}^{60} & \mathrm{p} & 10 & 1.0 \times 10^{3} & 1.0 \times 10^{2} \\ \mathrm{Hfb}_{2}{ }^{52,59} & \mathrm{n} & 100 & 5 \times 10^{6} & 5 \times 10^{4} \\ \mathrm{~B}_{6.5} \mathrm{C}^{27, a} & \mathrm{p} & 3.0 & 5.0 \times 10^{4} & 1.7 \times 10^{4} \\ \mathrm{Yb}_{66} \mathrm{C}_{0.6}{ }^{55} & \mathrm{p} & 1.5 & 250 & 1.7 \times 10^{2} \\ \mathrm{Erb}_{44} \mathrm{Si}_{2}{ }^{70} & \mathrm{p} & 1.6 & 1.4 \times 10^{3} & 8.8 \times 10^{2} \\ \mathrm{Ca}_{0.5} \mathrm{Sr}_{0.5} \mathrm{~B}_{6}{ }^{28} & \mathrm{n} & 8.9 & 1.0 \times 10^{5} & 1.1 \times 10^{4} \\ \mathrm{Hob}_{17} \mathrm{Cn}^{71} & \mathrm{n} & 1.7 & 1.1 & 0.6 \\ { }^{a} 1250{\mathrm{~K} \mathrm{for} \mathrm{B}_{6.5} \mathrm{C} .}^{25} & & & & \end{array}$

$\mathrm{HfB}_{2}$ and $\beta$-B references provide benchmarks to address the properties of the nanocomposites we designed. A large increase in $\sigma / \kappa$ by 2 orders of magnitude is observed when compared to $\beta$-B, due to enhanced electrical conductivity, whereas the thermal conductivities are similar. $\sigma / \kappa$ values of the nanocomposites are similar to those of bulk $\mathrm{HfB}_{2}$, but they reflect a 2 orders of magnitude decrease of both $\sigma$ and $\kappa$ in the case of the sample 1:6-1200-100. The deteriorated metallic behavior compared to that of bulk $\mathrm{HfB}_{2}$ is a prerequisite to improved thermoelectric properties. The electrical conductivitiy of sample 1:6-1200-100 is indeed comparable to those of reference boron-rich thermoelectric materials (Table 2), despite being composed of a large fraction of metallic $\mathrm{HfB}_{2}$ (33 vol \%). The overall ratio $\sigma / \kappa$ is higher than most boronbased materials scrutinized for their thermoelectric properties, thus showing the large decoupling of electrical and thermal properties achieved in the nanocomposites. The nanocomposites have unusual transport properties combining electrical metallic behavior associated with $\mathrm{HfB}_{2}$ nanocrystals and thermal insulating properties common to boron-rich phases.

The sample 1:4 synthesized with a large $\mathrm{HfB}_{2}$ volume fraction (41 vol \%) above the percolation threshold expectedly shows electrical properties driven by the metallic $\mathrm{HfB}_{2}$ component but with a lower $\kappa$ attributed to the insulating boron-rich matrix and to phonon scattering by the nanostructure. The similar behavior of the sample 1:6 despite being at the edge of the percolation threshold after synthesis may be related to the loss of volatile components from the initial amorphous shell. This evolution yields an increase in the $\mathrm{HfB}_{2}$ volume fraction, which may then reach values higher than the percolation ratio.

\section{CONCLUSIONS}

We have shown that synthesis in inorganic molten salts is a unique tool to enable the one-pot design of boron-based coreshell nanoparticles with an adjustable volume fraction of core and shell constituents. This versatility combined with the 
efficiency of spark plasma sintering to yield dense monoliths while maintaining the size of nanoinclusions results in distinct electrical and thermal conductivities, with a strong decoupling between both transport properties. In addition, the sintering step evidences significant structural reorganization in an amorphous boron-rich component, which will be studied in the future. All in all, this work provides a new avenue for the future design of nanostructured monolithic boron-rich composites with tunable properties, encompassing electrical and thermal properties but also mechanical properties.

\section{EXPERIMENTAL SECTION}

Powder Synthesis. $\mathrm{LiCl}$ (99\%), $\mathrm{KCl}$ (99\%), $\mathrm{NaBH}_{4}$ (98\%), and anhydrous $\mathrm{HfCl}_{4}$ (99.9\%) were purchased from Alfa Aesar. In an argon-filled glovebox (MBraun), boron and hafnium precursors were added to a mixture of $\mathrm{LiCl} / \mathrm{KCl}$ at the eutectic composition $(45 / 55$ wt \%) previously dried under a vacuum at $200{ }^{\circ} \mathrm{C}$ during $48 \mathrm{~h}$. For each synthesis, the quantities used are reported in Table S1. The mixture was ball milled for $2 \mathrm{~min}$ at $20 \mathrm{~Hz}$ using a MM400 (Retsch) container and stainless-steel balls. The resulting powder was transferred in a glassy carbon crucible, and the crucible was maintained in a quartz tube. The setup was connected to an argon ramp. The reaction medium was heated to $900{ }^{\circ} \mathrm{C}$ in a vertical oven (Carbolite) for $4 \mathrm{~h}$ after a $10{ }^{\circ} \mathrm{C} \cdot \mathrm{min}^{-1} \mathrm{ramp}$ from RT. The medium was mixed during the experiment, using a glassy carbon rod rotating at approximately $120 \mathrm{rpm}$. After heating, the medium was left to cool naturally to RT. Under air, the solidified salt medium was washed three times by successive dispersion in deionized water, sonicated for few minutes in an USC100TH (VWR) ultrasonic bath, and centrifuged for $15 \mathrm{~min}$ at 22 to $26 \mathrm{krpm}$ (Sigma 3-30k), and the supernatant was discarded. The black powder was dried under vacuum overnight at $60{ }^{\circ} \mathrm{C}$ and stored under air. Up to $400 \mathrm{mg}$ of powder is obtained per synthesis.

Spark Plasma Sintering. Spark plasma sintering experiments were performed on a $515 S$ Syntex (Dr. Sinter) apparatus. In a typical procedure, $1 \mathrm{~g}$ of $\mathrm{HfB}_{2}$-based nanocomposite was introduced in a graphite die (inner diameter of $8 \mathrm{~mm}$ ) covered with Papyex. The SPS chamber was maintained under an argon flow at $1 \mathrm{~atm}$ during the experiment. The uniaxial pressure of $5 \mathrm{kN}(100 \mathrm{MPa})$ or $6.5 \mathrm{kN}(130$ $\mathrm{MPa}$ ) was applied at $0.5 \mathrm{kN} \cdot \mathrm{min}^{-1}$ prior to heating at $600{ }^{\circ} \mathrm{C}$. A heating ramp of $100{ }^{\circ} \mathrm{C} \cdot \mathrm{min}^{-1}$ was then applied up to temperatures ranging from 800 to $1800{ }^{\circ} \mathrm{C}\left(107{ }^{\circ} \mathrm{C} \cdot \mathrm{min}^{-1}\right.$ for $\left.1350{ }^{\circ} \mathrm{C}\right)$. The sample was maintained for $1 \mathrm{~min}$ at the dwell temperature. The pressure was released to $0.5 \mathrm{kN}$ (minimal charge) in $3 \mathrm{~min}$, and the apparatus cooled naturally under argon in $20 \mathrm{~min}$. A polishing step was required to remove the carbon layer from Papyex, using abrasive $\mathrm{SiC}$ sandpapers with increasing grit sizes from 120 to 1200 .

Transmission Electron Microscopy (TEM). A $120 \mathrm{kV}$ Tecnai Spirit microscope was used for TEM and selected area electron diffraction (SAED) pictures. High resolution-TEM (HRTEM) was also operated on a $200 \mathrm{kV} \mathrm{JEOL} \mathrm{JEM} 2011$ apparatus, at the Institut des Matériaux de Paris Centre. Samples were prepared by evaporating a drop of suspension in ethanol on a carbon-coated copper grid. Core and shell size distributions were obtained from measurements on at least 100 particles with pictures from three different regions of the grid. For simplicity, the $\mathrm{HfB}_{2}$ volume fraction is calculated from the average core diameter and shell thickness measurements. The SAED pattern was indexed along the $\mathrm{HfB}_{2}$ structure (ICDD file 00-0381398).

X-ray Diffraction (XRD). Measurements were performed on a D8 Bruker apparatus operating at the $\mathrm{Cu} \mathrm{K} \alpha_{1} / \mathrm{K} \alpha_{2}$ radiations, acceleration tension of $45 \mathrm{kV}$, working current of $40 \mathrm{~mA}, 10 \leq 2 \theta$ $\leq 80^{\circ}$ with $0.05^{\circ}$ steps, and counting time of $2 \mathrm{~s}$ per step. Patterns were indexed according to the ICDD files: $\mathrm{HfB}_{2}(00-038-1398)$ and $\mathrm{HfO}_{2}$ (00-043-1017). Apparent crystallite sizes $\varepsilon$ were calculated using the Scherrer formula and pseudo-Voigt functions to fit peaks. Le Bail refinements were performed on JANA2006 software. ${ }^{72}$
Scanning Electron Microscopy (SEM) and Energy Dispersive X-ray Spectrometry (EDS). A SU-70 (Hitachi) field emission SEM operating at $5 \mathrm{kV}$ was used for imaging powders deposited on conductive and adhesive tape. Pellets were observed from their basal surfaces. Samples were covered with a carbon layer of approximately $20 \mathrm{~nm}$ by thermal evaporation. Energy dispersive X-ray analyses were performed with a S-3400-N (Hitachi) SEM operating at $10 \mathrm{kV}$ and equipped with an X-Max EDS system (Oxford Instruments) utilizing a large area $\left(20 \mathrm{~mm}^{2}\right)$ analytical silicon drift EDS detector. The beam current was measured in order to test the quality of the spectra to be quantified. X-ray lines used for quantification were $\mathrm{B} \mathrm{K}, \mathrm{O} \mathrm{K}$, and $\mathrm{Hf}$ $\mathrm{M}$. The quantitative data are the average of four measurements in different regions. Elemental composition of pristine powder with standard deviations: Hf: 20(2) atom \%; B: 63(1) atom \%; O: 17(2) atom \%.

Inductive Coupled Plasma-Optical Emission Spectrometry. ICP-OES measurements were acquired on an iCAP 6000 apparatus (ThermoFischer). The hafnium diboride powder was dissolved in a 5 $\mathrm{mol} \cdot \mathrm{L}^{-1}$ nitric acid solution. Each elemental concentration shown is the average of three measurements.

Volumetric Mass Density. For pellets, the volumetric mass density was calculated from hydrostatic pycnometry consisting of three mass measurements of the pellet (i) dried, (ii) immerged in deionized water at $25{ }^{\circ} \mathrm{C}$, and (iii) wet with excess water removed with a tissue. Helium pycnometry was performed to measure the density of powders, using a Ultrapyc 1200e (Quantachrome Corporation).

Calculation of the Maximal Density Expected for Pellets Sintered at $1350{ }^{\circ} \mathrm{C}$ and above $\left(d_{\text {thr }}\right)$. For calculating $d_{\text {thr }}$, we considered a composite made of $\mathrm{HfB}_{2}\left(d\left(\mathrm{HfB}_{2}\right)=11.21 \mathrm{~g} \cdot \mathrm{cm}^{-3}\right)^{52}$ and amorphous boron $\left(d(\mathrm{~B})=2.37 \mathrm{~g} \cdot \mathrm{cm}^{-3}\right){ }^{31}$ The specific volume of the composite is the volume occupied by the $\mathrm{HfB}_{2}$ component added to the volume of amorphous boron for $1 \mathrm{~g}$ of composite:

$$
V=\frac{m\left(\mathrm{HfB}_{2}\right)}{d\left(\mathrm{HfB}_{2}\right)}+\frac{m(\mathrm{~B})}{d(\mathrm{~B})}
$$

EDS measurements on the pellets sintered at 1350 and $1800{ }^{\circ} \mathrm{C}$ indicated a $\mathrm{B} / \mathrm{Hf}$ molar ratio of 3:1. From this ratio we deduced that 65 atom \% of boron is in $\mathrm{HfB}_{2}$ and the remaining 35 atom \% is in the shell. The proportions of the two phases are then $94.2 \mathrm{wt} \%$ of $\mathrm{HfB}_{2}$ and $5.8 \mathrm{wt} \%$ of B. Then, the specific volume of the composite is $V=$ $0.108 \mathrm{~cm}^{-3} \cdot \mathrm{g}^{-1}$, which corresponds to a density $d_{\mathrm{thr}}=9.21 \mathrm{~g} \cdot \mathrm{cm}^{-3}$.

Thermal Conductivity. Thermal conductivity was measured on cylindrical pellets, $8.0 \mathrm{~mm}$ in diameter and 1.2 to $3.0 \mathrm{~mm}$ thick, under nitrogen $\left(20 \mathrm{~mL} \cdot \mathrm{min}^{-1}\right)$, using a Laser Flash Apparatus 457 MicroFlash (Netzsch) at $1054 \mathrm{~nm}$ and equipped with an InSb infrared detector. At each temperature, three consecutive measurements were averaged. Calorific capacities per unit mass were calculated as a function of temperature from the tabulated molar calorific capacities of hafnium diboride and elemental boron (beta) accessible on the National Institute of Standards and Technology database, ${ }^{73}$ taking mass fractions of the composite into account. Porosity has an effect on transport properties such as electrical $(\sigma)$ and thermal $(\kappa)$ conductivities. The contribution of pores can be deduced using the Maxwell-Eucken equation, giving access to the corrected values of conductivity $t^{*}$ :

$$
t^{*}=t \frac{1+\beta P}{1-P}
$$

$t$ is either $\sigma$ or $\kappa$, the porosity $P$ delineates a limit of application of the equation with $P_{\max }=0.2$, and $\beta$ is an empirical form factor that reflects the influence of the pore geometry. It ranges from 1 to 3 and is fixed at 2 , as reported in other studies with similar geometries. ${ }^{18,27,74}$ Accordingly, the correction factor ranges from 1 for a fully densified pellet to 1.75 for $P_{\max }=0.2$.

Seebeck Coefficient and Electrical Conductivity. The Seebeck coefficient and electrical conductivity were measured on rectangular rods shaped with a Isomet 5000 (Buehler) circular saw, using a ZEM-3 (ULVAC-RIKO) apparatus. At each temperature, one 
measurement was performed with $\Delta T=0$ for resistivity measurements, followed by three measurements with $\Delta T \neq 0$ for Seebeck measurements. The porosity effect on the electrical conductivity has been evaluated the same way as for thermal conductivity, detailed above.

\section{Supporting Information}

Table S1 summarizing synthesis conditions, Table S2 reporting $\mathrm{HfB}_{2}$ cell parameters, and Figures $\mathrm{S} 1-\mathrm{S} 6$ for additional characterization (PDF)

\section{Corresponding Author}

David Portehault - Sorbonne Université, CNRS, College de France, Laboratoire Chimie de la Matière Condensée de Paris, LCMCP, F-75005 Paris, France; (1) orcid.org/00000003-4914-4913; Email: david.portehault@sorbonneuniversite.fr

\section{Authors}

Guillaume Gouget - Sorbonne Université, CNRS, College de France, Laboratoire Chimie de la Matière Condensée de Paris, LCMCP, F-75005 Paris, France; 이이.org/00000002-6446-001X

Damien Bregiroux - Sorbonne Université, CNRS, College de France, Laboratoire Chimie de la Matière Condensée de Paris, LCMCP, F-75005 Paris, France

Rémi Grosjean - Sorbonne Université, CNRS, College de France, Laboratoire Chimie de la Matière Condensée de Paris, LCMCP, F-75005 Paris, France; Sorbonne Université, CNRS, MNHN, IRD, Institut de Minéralogie, de Physique des Matériaux et de Cosmochimie, IMPMC, F-75005 Paris, France

David Montero - Sorbonne Université CNRS, Institut des Matériaux de Paris Centre, IMPC, F-75005 Paris, France

Stefan Maier - Laboratoire CRISMAT UMR 6508 CNRS ENSICAEN, 14050 Cedex 04 Caen, France

Franck Gascoin - Laboratoire CRISMAT UMR 6508 CNRS ENSICAEN, 14050 Cedex 04 Caen, France; ㅇorcid.org/ 0000-0002-9791-1358

Clément Sanchez - Sorbonne Université, CNRS, College de France, Laboratoire Chimie de la Matière Condensée de Paris, LCMCP, F-75005 Paris, France; 이이.org/00000002-6426-4844

\section{ACKNOWLEDGMENTS}

The authors acknowledge Benjamin Villeroy from the Institut de Chimie de Matériaux Paris-Est for his help for helium pycnometry. This work was funded by the Ministère de l'Enseignement Supérieure et de la Recherche and the CNRS. The authors also thank Sorbonne Université and C'Nano projects of the Région Ile-de-France for additional funding.

\section{REFERENCES}

(1) Liu, X.; Deng, Y. D.; Li, Z.; Su, C. Q. Performance Analysis of a Waste Heat Recovery Thermoelectric Generation System for Automotive Application. Energy Convers. Manage. 2015, 90, 121-127.

(2) Zhang, J.; Xuan, Y.; Yang, L. Performance Estimation of Photovoltaic-Thermoelectric Hybrid Systems. Energy 2014, 78, 895-903.

(3) Sootsman, J. R.; Chung, D. Y.; Kanatzidis, M. G. New and Old Concepts in Thermoelectric Materials. Angew. Chem., Int. Ed. 2009, 48 (46), 8616-8639.

(4) Chester, G. V.; Thellung, A. The Law of Wiedemann and Franz. Proc. Phys. Soc., London 1961, 77 (5), 1005-1013.

(5) DiSalvo, F. J. Thermoelectric Cooling and Power Generation. Science 1999, 285 (5428), 703-706.

(6) Liu, Z.; Mao, J.; Liu, T.-H.; Chen, G.; Ren, Z. NanoMicrostructural Control of Phonon Engineering for Thermoelectric Energy Harvesting. MRS Bull. 2018, 43 (3), 181-186.

(7) Mori, T. Novel Principles and Nanostructuring Methods for Enhanced Thermoelectrics. Small 2017, 13 (45), 1702013.

(8) He, J.; Tritt, T. M. Advances in Thermoelectric Materials Research: Looking Back and Moving Forward. Science 2017, 357 (6358), eaak9997.

(9) Venkatasubramanian, R.; Siivola, E.; Colpitts, T.; O'Quinn, B. Thin-Film Thermoelectric Devices with High Room-Temperature Figures of Merit. Nature 2001, 413 (6856), 597-602.

(10) Tang, X.; Xie, W.; Li, H.; Zhao, W.; Zhang, Q.; Niino, M. Preparation and Thermoelectric Transport Properties of HighPerformance p-Type $\mathrm{Bi}_{2} \mathrm{Te}_{3}$ with Layered Nanostructure. Appl. Phys. Lett. 2007, 90 (1), 012102.

(11) Kulbachinskii, V. a.; Kytin, V. G.; Popov, M. Y.; Buga, S. G.; Stepanov, P. B.; Blank, V. D. Composites of $\mathrm{Bi}_{(2-\mathrm{x})} \mathrm{Sb}_{\mathrm{x}} \mathrm{Te}_{3}$ Nanocrystals and Fullerene Molecules for Thermoelectricity. J. Solid State Chem. 2012, 193, 64-70.

(12) Hsu, K. F.; Loo, S.; Guo, F.; Chen, W.; Dyck, J. S.; Uher, C.; Hogan, T.; Polychroniadis, E. K.; Kanatzidis, M. C. Cubic $\mathrm{AgPb}_{\mathrm{m}} \mathrm{SbTe}_{(2+\mathrm{m})}$ : Bulk Thermoelectric Materials with High Figure of Merit. Science 2004, 303 (5659), 818-821.

(13) Sootsman, J. R.; Pcionek, R. J.; Kong, H.; Uher, C.; Kanatzidis, M. G. Strong Reduction of Thermal Conductivity in Nanostructured $\mathrm{PbTe}$ Prepared by Matrix Encapsulation. Chem. Mater. 2006, 18 (21), 4993-4995.

(14) Sootsman, J. R.; Kong, H.; Uher, C.; D’Angelo, J. J.; Wu, C. I.; Hogan, T. P.; Caillat, T.; Kanatzidis, M. G. Large Enhancements in the Thermoelectric Power Factor of Bulk PbTe at High Temperature by Synergistic Nanostructuring. Angew. Chem., Int. Ed. 2008, 47 (45), $8618-8622$.

(15) Hao, Q.; Zhu, G.; Joshi, G.; Wang, X.; Minnich, A.; Ren, Z.; Chen, G. Theoretical Studies on the Thermoelectric Figure of Merit of Nanograined Bulk Silicon. Appl. Phys. Lett. 2010, 97 (6), 063109.

(16) Dresselhaus, M. S.; Chen, G.; Tang, M. Y.; Yang, R.; Lee, H.; Wang, D.; Ren, Z.; Fleurial, J. P.; Gogna, P. New Directions for LowDimensional Thermoelectric Materials. Adv. Mater. 2007, 19 (8), $1043-1053$.

(17) Kovalenko, M. V.; Spokoyny, B.; Lee, J.-S.; Scheele, M.; Weber, A.; Perera, S.; Landry, D.; Talapin, D. V. Semiconductor Nanocrystals Functionalized with Antimony Telluride Zintl Ions for Nanostructured Thermoelectrics. J. Am. Chem. Soc. 2010, 132 (19), 6686-6695.

(18) Ibáñez, M.; Zamani, R.; Gorsse, S.; Fan, J.; Ortega, S.; Cadavid, D.; Morante, J. R.; Arbiol, J.; Cabot, A. Core-Shell Nanoparticles As Building Blocks for the Bottom-Up Production of Functional Nanocomposites: $\mathrm{PbTe}-\mathrm{PbS}$ Thermoelectric Properties. ACS Nano 2013, 7 (3), 2573-2586.

(19) See, K. C.; Feser, J. P.; Chen, C. E.; Majumdar, A.; Urban, J. J.; Segalman, R. A. Water-Processable Polymer-Nanocrystal Hybrids for Thermoelectrics. Nano Lett. 2010, 10 (11), 4664-4667.

(20) Yu, C.; Kim, Y. S.; Kim, D.; Grunlan, J. C. Thermoelectric Behavior of Segregated-Network Polymer Nanocomposites. Nano Lett. 2008, 8 (12), 4428-4432. 
(21) Dismukes, J. P.; Ekstrom, L.; Steigmeier, E. F.; Kudman, I.; Beers, D. S. Thermal and Electrical Properties of Heavily Doped GeSi Alloys up to 1300 K. J. Appl. Phys. 1964, 35 (10), 2899.

(22) Wood, C. Materials for Thermoelectric Energy Conversion. Rep. Prog. Phys. 1988, 51, 459.

(23) Brown, S. R.; Kauzlarich, S. M.; Gascoin, F.; Snyder, G. J. $\mathrm{Yb}_{14} \mathrm{MnSb}_{11}$ : New High Efficiency Thermoelectric Material for Power Generation. Chem. Mater. 2006, 18 (7), 1873-1877.

(24) Chamoire, A.; Gascoin, F.; Estournès, C.; Caillat, T.; Tédenac, J.-C. High-Temperature Transport Properties of $\mathrm{Yb}_{4-\mathrm{x}} \mathrm{Sm}_{\mathrm{x}} \mathrm{Sb}_{3}$. J. Electron. Mater. 2010, 39 (9), 1579-1582.

(25) Chamoire, A.; Gascoin, F.; Estournès, C.; Caillat, T.; Tédenac, J.-C. High-Temperature Transport Properties of Complex Antimonides with Anti- $\mathrm{Th}_{3} \mathrm{P}_{4}$ Structure. Dalt. Trans. 2010, 39 (4), 11181123.

(26) May, A. F.; Fleurial, J.-P.; Snyder, G. J. Thermoelectric Performance of Lanthanum Telluride Produced via Mechanical Alloying. Phys. Rev. B: Condens. Matter Mater. Phys. 2008, 78 (12), 125205.

(27) Bouchacourt, M.; Thevenot, F. The Correlation between the Thermoelectric Properties and Stoichiometry in the Boron Carbide Phase $\mathrm{B}_{4} \mathrm{C}-\mathrm{B}_{10.5}$ C. J. Mater. Sci. 1985, 20 (4), 1237-1247.

(28) Takeda, M.; Terui, M.; Takahashi, N.; Ueda, N. Improvement of Thermoelectric Properties of Alkaline-Earth Hexaborides. J. Solid State Chem. 2006, 179 (9), 2823-2826.

(29) Gürsoy, M.; Takeda, M.; Albert, B. High-Pressure Densified Solid Solutions of Alkaline Earth Hexaborides ( $\mathrm{Ca} / \mathrm{Sr}, \mathrm{Ca} / \mathrm{Ba}, \mathrm{Sr} / \mathrm{Ba}$ ) and Their High-Temperature Thermoelectric Properties. J. Solid State Chem. 2015, 221, 191-195.

(30) Fahrenholtz, W. G.; Hilmas, G. E.; Talmy, I. G.; Zaykoski, J. A. Refractory Diborides of Zirconium and Hafnium. J. Am. Ceram. Soc. 2007, 90 (5), 1347-1364.

(31) Albert, B.; Hillebrecht, H. Boron: Elementary Challenge for Experimenters and Theoreticians. Angew. Chem., Int. Ed. 2009, 48 (46), 8640-8668.

(32) Mori, T. Perspectives of High-Temperature Thermoelectric Applications and p-Type and n-Type Aluminoborides. JOM 2016, 68 (10), 2673-2679.

(33) Slack, G. A.; Morgan, K. E. Some Crystallography, Chemistry, Physics, and Thermodynamics of $\mathrm{B}_{12} \mathrm{O}_{2}, \mathrm{~B}_{12} \mathrm{P}_{2}, \mathrm{~B}_{12} \mathrm{As}_{2}$, and Related Alpha-Boron Type Crystals. J. Phys. Chem. Solids 2014, 75 (9), 10541074.

(34) Mori, T.; Nishimura, T.; Schnelle, W.; Burkhardt, U.; Grin, Y. The Origin of the N-Type Behavior in Rare Earth Borocarbide $\mathrm{Y}_{1-\mathrm{x}} \mathrm{B}_{28.5} \mathrm{C}_{4}$. Dalt. Trans. 2014, 43 (40), 15048-15054.

(35) Sauerschnig, P.; Vaney, J. B.; Michiue, Y.; Kouzu, K.; Yamasaki, T.; Okada, S.; Yoshikawa, A.; Shishido, T.; Mori, T. Thermoelectric and Magnetic Properties of Spark Plasma Sintered $\mathrm{REB}_{66}(\mathrm{RE}=\mathrm{Y}$, Sm, Ho, Tm, Yb). J. Eur. Ceram. Soc. 2020, 40 (10), 3585-3591.

(36) Werheit, H. Boron-Rich Solids: A Chance for High-Efficiency High-Temperature Thermoelectric Energy Conversion. Mater. Sci. Eng., B 1995, 29 (1-3), 228-232.

(37) Innocent, J.-L.; Portehault, D.; Gouget, G.; Maruyama, S.; Ohkubo, I.; Mori, T. Thermoelectric Properties of Boron Carbide/ $\mathrm{HfB}_{2}$ Composites. Mater. Renew. Sustain. Energy 2017, 6 (2), 6.

(38) Mori, T.; Hara, T. Hybrid Effect to Possibly Overcome the Trade-off between Seebeck Coefficient and Electrical Conductivity. Scr. Mater. 2016, 111, 44-48.

(39) Carenco, S.; Portehault, D.; Boissière, C.; Mézailles, N.; Sanchez, C. Nanoscaled Metal Borides and Phosphides: Recent Developments and Perspectives. Chem. Rev. 2013, 113, 7981-8065.

(40) Portehault, D.; Delacroix, S.; Gouget, G.; Grosjean, R.; ChanChang, T.-H.-C. Beyond the Compositional Threshold of Nanoparticle-Based Materials. Acc. Chem. Res. 2018, 51 (4), 930-939.

(41) Jothi, P. R.; Yubuta, K.; Fokwa, B. P. T. A Simple, General Synthetic Route toward Nanoscale Transition Metal Borides. Adv. Mater. 2018, 30, 1704181.
(42) Mori, T. Thermoelectric and Magnetic Properties of Rare Earth Borides: Boron Cluster and Layered Compounds. J. Solid State Chem. 2019, 275, 70-82.

(43) Portehault, D.; Devi, S.; Beaunier, P.; Gervais, C.; Giordano, C.; Sanchez, C.; Antonietti, M. A General Solution Route toward Metal Boride Nanocrystals. Angew. Chem., Int. Ed. 2011, 50 (14), 32623265.

(44) Gouget, G.; Beaunier, P.; Portehault, D.; Sanchez, C. New Route toward Nanosized Crystalline Metal Borides with Tunable Stoichiometry and Variable Morphologies. Faraday Discuss. 2016, 191, 511-525.

(45) Gouget, G.; Debecker, D. P.; Kim, A.; Olivieri, G.; Gallet, J.-J.; Bournel, F.; Thomas, C.; Ersen, O.; Moldovan, S.; Sanchez, C.; Carenco, S.; Portehault, D. In Situ Solid-Gas Reactivity of Nanoscaled Metal Borides from Molten Salt Synthesis. Inorg. Chem. 2017, 56 (15), 9225-9234.

(46) Grosjean, R.; Le Godec, Y.; Delacroix, S.; Gouget, G.; Beaunier, P.; Ersen, O.; Ihiawakrim, D.; Kurakevych, O. O.; Chanéac, C.; Portehault, D. A High Pressure Pathway toward Boron-Based Nanostructured Solids. Dalt. Trans. 2018, 47 (23), 7634-7639.

(47) Son, H.-W.; Berthebaud, D.; Yubuta, K.; Yoshikawa, A.; Shishido, T.; Suzuta, K.; Mori, T. New Synthesis Route for Complex Borides; Rapid Synthesis of Thermoelectric Yttrium Aluminoboride via Liquid-Phase Assisted Reactive Spark Plasma Sintering. Sci. Rep. 2020, 10 (1), 8914.

(48) Portehault, D.; Maneeratana, V.; Candolfi, C.; Oeschler, N.; Veremchuk, I.; Grin, Y.; Sanchez, C.; Antonietti, M. Facile General Route toward Tunable Magnéli Nanostructures and Their Use as Thermoelectric Metal Oxide/Carbon Nanocomposites. ACS Nano 2011, 5 (11), 9052-9061.

(49) Anselmi-Tamburini, U.; Garay, J. E.; Munir, Z. A.; Tacca, A.; Maglia, F.; Spinolo, G. Spark Plasma Sintering and Characterization of Bulk Nanostructured Fully Stabilized Zirconia: Part I. Densification Studies. J. Mater. Res. 2004, 19 (11), 3255-3262.

(50) Wang, L.; Zhang, J.; Jiang, W. Recent Development in Reactive Synthesis of Nanostructured Bulk Materials by Spark Plasma Sintering. Int. J. Refract. Hard Met. 2013, 39, 103-112.

(51) Cadavid, D.; Ibáñez, M.; Anselmi-Tamburini, U.; Durá, O. J.; López de laTorre, M. A.; Cabot, A. Thermoelectric Properties of Bottom-up Assembled $\mathrm{Bi}_{2} \mathrm{~S}_{(3-\mathrm{x})} \mathrm{Te}_{\mathrm{x}}$. Int. J. Nanotechnol. 2014, 11, 773.

(52) Zhang, L.; Pejaković, D. a.; Marschall, J.; Gasch, M. Thermal and Electrical Transport Properties of Spark Plasma-Sintered $\mathrm{HfB}_{2}$ and $\mathrm{ZrB}_{2}$ Ceramics. J. Am. Ceram. Soc. 2011, 94 (8), 2562-2570.

(53) Anselmi-Tamburini, U.; Kodera, Y.; Gasch, M.; Unuvar, C.; Munir, Z. A.; Ohyanagi, M.; Johnson, S. M. Synthesis and Characterization of Dense Ultra-High Temperature Thermal Protection Materials Produced by Field Activation through Spark Plasma Sintering (SPS): I. Hafnium Diboride. J. Mater. Sci. 2006, 41 (10), 3097-3104.

(54) Monteverde, F. Ultra-High Temperature $\mathrm{HfB}_{2}-\mathrm{SiC}$ Ceramics Consolidated by Hot-Pressing and Spark Plasma Sintering. J. Alloys Compd. 2007, 428 (1-2), 197-205.

(55) Mori, T.; Tanaka, T. Effect of Transition Metal Doping and Carbon Doping on Thermoelectric Properties of $\mathrm{YB}_{66}$ Single Crystals. J. Solid State Chem. 2006, 179 (9), 2889-2894.

(56) Berthebaud, D.; Nishimura, T.; Mori, T. Thermoelectric Properties and Spark Plasma Sintering of Doped $\mathrm{YB}_{22} \mathrm{C}_{2}$ N. J. Mater. Res. 2010, 25 (04), 665-669.

(57) Maruyama, S.; Prytuliak, A.; Miyazaki, Y.; Hayashi, K.; Kajitani, T.; Mori, T. Al Insertion and Additive Effects on the Thermoelectric Properties of Yttrium Boride. J. Appl. Phys. 2014, 115 (12), 123702.

(58) Gouget, G.; Debecker, D. P.; Kim, A.; Olivieri, G.; Gallet, J.-J.; Bournel, F.; Thomas, C.; Ersen, O.; Moldovan, S.; Sanchez, C.; Carenco, S.; Portehault, D. In Situ Solid-Gas Reactivity of Nanoscaled Metal Borides from Molten Salt Synthesis. Inorg. Chem. 2017, 56 (15), 9225-9234.

(59) Wuchina, E.; Opeka, M.; Causey, S.; Buesking, K.; Spain, J.; Cull, A.; Routbort, J.; Guitierrez-Mora, F. Designing for UltrahighTemperature Applications: The Mechanical and Thermal Properties 
of $\mathrm{HfB}_{2}, \mathrm{HfC}_{x}, \mathrm{HfN}_{\mathrm{x}}$ and $\alpha \mathrm{Hf}(\mathrm{N})$. J. Mater. Sci. 2004, 39 (19), 59395949.

(60) Takeda, M.; Fukuda, T.; Domingo, F.; Miura, T. Thermoelectric Properties of Some Metal Borides. J. Solid State Chem. 2004, 177 (2), 471-475.

(61) Berkemeier, F.; Voss, S.; Imre, Á. W.; Mehrer, H. Molar Volume, Glass-Transition Temperature, and Ionic Conductivity of $\mathrm{Na}-$ and $\mathrm{Rb}$-Borate Glasses in Comparison with Mixed $\mathrm{Na}-\mathrm{Rb}$ Borate Glasses. J. Non-Cryst. Solids 2005, 351 (52-54), 3816-3825.

(62) Lorenz, C. D.; Ziff, R. M. Precise Determination of the Critical Percolation Threshold for the Three-Dimensional "Swiss Cheese" Model Using a Growth Algorithm. J. Chem. Phys. 2001, 114 (8), 3659.

(63) Patterson, A. L. The Scherrer Formula for X-Ray Particle Size Determination. Phys. Rev. 1939, 56 (10), 978-982.

(64) Nguyen, H. G. T.; Horn, J. C.; Bleakney, M.; Siderius, D. W.; Espinal, L. Understanding Material Characteristics through Signature Traits from Helium Pycnometry. Langmuir 2019, 35 (6), 2115-2122.

(65) Munir, Z. A.; Anselmi-Tamburini, U.; Ohyanagi, M. The Effect of Electric Field and Pressure on the Synthesis and Consolidation of Materials: A Review of the Spark Plasma Sintering Method. J. Mater. Sci. 2006, 41 (3), 763-777.

(66) Matkovich, V. I. Boron and Refractory Borides; Springer-Verlag, Berlin, 1977, 207-208.

(67) Son, H.-W.; Sauerschnig, P.; Berthebaud, D.; Mori, T. Rapid Synthesis of Thermoelectric $\mathrm{YB}_{22} \mathrm{C}_{2} \mathrm{~N}$ via Spark Plasma Sintering with Gas/Solid Reaction Technology. J. Ceram. Soc. Jpn. 2020, 128 (4), 181-185.

(68) Slack, G. CRC Handbook of Thermoelectrics; CRC Press.; Rowe, D. M., Ed.; Boca Raton, FL, 1995, 407-440.

(69) Imai, Y.; Mukaida, M.; Ueda, M.; Watanabe, A. Screening of the Possible Boron-Based n-Type Thermoelectric Conversion Materials on the Basis of the Calculated Densities of States of Metal Borides and Doped $\beta$-Boron. Intermetallics 2001, 9 (8), 721-734.

(70) Mori, T. Thermal Conductivity of a Rare-Earth -Icosahedral Compound. Phys. B 2006, 383 (1), 120-121.

(71) Mori, T.; Nishimura, T. Thermoelectric Properties of Homologous P- and n-Type Boron-Rich Borides. J. Solid State Chem. 2006, 179 (9), 2908-2915.

(72) Petrícek, V.; Dušek, M.; Palatinus, L. Crystallographic Computing System JANA2006: General Features. Zeitschrift fur Krist. 2014, 229 (5), 345-352.

(73) Chase, M. W. NIST-JANAF Thermochemical Tables, 4th ed.; Journal of Physical and Chemical Reference Data; American Chemical Society and American Institute of Physics: 1998; Monogr. 9.

(74) Adachi, J.; Kurosaki, K.; Uno, M.; Yamanaka, S. Effect of Porosity on Thermal and Electrical Properties of Polycrystalline Bulk ZrN Prepared by Spark Plasma Sintering. J. Alloys Compd. 2007, 432 (1-2), 7-10. 